\title{
Immigrating to Northeast America: The Kenyan Immigrants' Experience
}

\author{
Jane Kabuiku \\ Walden University
}

Immigrants lose their unique psychosocial context when their experiences are subsumed under panethnic labels such as Hispanic, Latina/o, Asian, or African. The stress from navigating different cultural contexts becomes problematic when immigrants operate within mainstream cultural norms that are in conflict with their traditional values. The number of Kenyan immigrants to the United States has steadily increased since the 1980s. The purpose of this descriptive phenomenological study was to study the lived experience of Kenyan immigrants by focusing on their integration experience and how the integration processes may have affected their mental functioning. Transition theory and social constructionism theory were used as the theoretical lens for this study. Data were collected using semistructured interviews conducted with seven Kenyan men and women over the age of 18 from the Northeastern United States who had immigrated from 1996 to the present day. Coding was used to analyze the data by cross-case analysis to search for themes and patterns. Data analysis revealed discrimination, alienation, shame, overcompensation, and cultural shock from the Kenyan immigrants' perspective.

Keywords: immigrants, mental functioning, psychological distress, mental health issues, minority stress, African immigrants, African culture, transition theory, social constructionism theory

\section{Introduction}

Migration provides an influx of human resources, intellectual capital, and cultural diversity into receiving countries (Goff, Zarin, \& Goodman, 2012). Immigrants contribute not only to economic expansion but also to the political and cultural vibrancy (Díaz, 2011). Approximately 40,000,000 immigrants live in the United States (Passel \& Cohn, 2012). Immigrants move to America for better legal and civil rights, job and educational prospects, to reunite with loved ones, to have a home in the United States, and because they desire an American identity (Amuedo-Dorantes, Puttitanun, \& Martinez-Donate, 2013). Ruiz, Gallardo, and Delgado-Romero (2013) posited that immigrants are in pursuit of economic opportunity and political and religious freedom.

African immigrants move for the same reasons as most migrants from other parts of the world. Idemudia, Williams, and Wyatt (2013) found that immigrants from Zimbabwe to South Africa frequently cited economic prospects as significant reasons to leave behind their families, friends, and community. They also found that wars, political instability, and civil unrest were an impetus for migration to other countries. Bándy (2011) and Thomas (2011) both cited political and economic instability as well as natural disasters and their impact on refugee movement as key determinants of African migration to the United States. Nwoye (2009) posited that immigrants from Africa to North America are driven by the belief that America is an ideal country where they will discover opportunities which will make a considerable difference in their lives. Lister (2010) proposed that, in 
some cases, Africans immigrate to escape certain cultural practices such as forced marriages or female genital mutilation, which may be considered outdated and inhumane in modern society.

Past studies indicate that around 500 Africans arrived every year in the United States between 1861 and 1961 (Konadu-Agyemang, Takyi, \& Arthur, 2006). The number of immigrants to North America who were born in Africa grew from 200,000 to over 1,000,000 between 1980 and 2009; Africans make up approximately $4 \%$ of the 38,500,000 immigrants in the United States (McCabe, 2011). Most African immigrants come to North America from Nigeria, Egypt, Ghana, Kenya, and Ethiopia (McCabe, 2011). At least 75\% of African-born migrants have arrived in the United States since 1991(McCabe, 2011).

The United States Embassy in Kenya issued slightly over 250,000 visas to Kenyans in the last 21 years (Karanja, 2014). Many Kenyan Green Card recipients who immigrated to the United States during this period successfully petitioned for their relatives to join them. This action led to the issuance of over 5,000 immigrant visas (Karanja, 2014). These numbers do not include Kenyans who entered as students who are now permanent residents or United States citizens, nor those who entered the country as business people or as tourists but later chose to stay (Karanja, 2014). Like other immigrants, Kenyans move for political, religious, economic, or cultural reasons that have forced many to leave their families and social structure.

Immigration is a major life shift that can be a source of significant stress leading to psychosocial health issues if not handled well (David, Nadal, \& Kevin, 2013; Goff et al., 2012; Koning, 2011). Immigration has been shown to be a major risk factor for psychological distress and mental disorders (Nwoye, 2009). This study is aimed at understanding the issues underlying the increase in psychosocial issues among immigrants of Kenyan origin. In the recent past, there has been disturbing news reports among Kenyan immigrants in the United States: a Kenyan man in Georgia was accused of killing his mother-in-law and then turning the gun on himself; in Indiana, a 6-yearold was stabbed to death while her mother suffered several stab wounds allegedly at the hands of the girl's father; and a Maryland judge found a Kenyan mechanical engineering student who killed his housemate not criminally responsible due to mental illness. In other news reports, a Kenyan mother and her two children were found killed in an apartment in Minnesota with the woman's husband and father of the children confessing to the crimes. Nwoye found that when mental issues among African immigrants are not addressed, they negatively impact an already difficult cultural assimilation experience. Nwoye also found disparity between the preconceived ideas held by African migrants as they settle in the new country and the actual reality in which they found themselves. With this conflict, the result is destabilization, depression, cognitive discord, and confusion resulting from the efforts to adapt to a new environment and the demands from work and family (Nwoye, 2009). Work demands, family needs, changing family structure, establishing social interactions, general health issues, and learning a new language are major stressors for immigrants (Renzaho \& Vignjevic, 2011). This study highlights the impact of the integration process on emerging psychosocial issues among Kenyans in the United States. This study was conducted with participants from the Northeastern United States. Participants were from Pennsylvania, New Jersey, Maryland, Massachusetts, and Virginia.

\section{Literature Review}

This literature review will focus on the existing literature and research regarding the immigration and mental functioning of African and other immigrants. Summaries of studies on the immigrants' perceived mental health were examined to help outline the transition and social constructionism theories and how they relate to understanding the mental health phenomena among immigrants. 
Studies addressing the perspective and lived experiences of immigrants leading to psychological distress were of particular interest. Sources from multiple databases such as Proquest, ERIC, PsycARTICLES, PsycINFO, SocINDEX with Full Text, and EBSCOHost were used in the completion of this review. Keywords and descriptors used include immigrants, mental state, mental functioning, mental health issues, minority stress, African immigrants, African culture, transition theory, social constructionism theory, and other relevant terms.

\section{The African Immigrants Vision and Disillusion}

When an African migrates, the community views this as a chance for promotion, growth, and improvement of their lives (Nwoye, 2009). The expectation of such relatives is based on the collectivist culture where an individual's success is viewed as communal (Sue \& Sue, 2013). The African immigrant leaves for the United States or similar destinations with a great sense of trepidation at what the future holds (Nwoye, 2009). For those who are not able to achieve the success they had anticipated when they set out on this journey, the result is despair, decline, confusion, and cognitive discord (Nwoye, 2009).

\section{Absence of Social Support}

The loss of social support has a detrimental impact on most immigrants (Katsiaficas, Suárez-Orozco, Sirin, \& Gupta, 2013; Makwarimba et al., 2013). Collectivist societies offer an abundance of social support through neighbors and relatives (Sue \& Sue, 2013). Upon arrival in the United States, African immigrants encounter little or no support; they experience separation from their families, trouble forming new relations, limited access to essential facilities, and lack of culturally appropriate linguistic services (Makwarimba et al., 2013). Other issues compounding the immigrant's dilemma are inadequate information or misinformation, changes in immigration status, which can affect some immigrant's access to health and educational benefits (Makwarimba et al., 2013).

\section{Acculturative Stress}

Culture is integral to the successful integration of an immigrant into the host community. Latin American, Asian, and African cultures have been identified as collectivist cultures (Sue \& Sue, 2013). There may be some aspects of culture that are critical to maintaining resilience, whereas others may be irrelevant to such benefits (Ruiz et al., 2013). In the Asian culture, factors such as shame and collectivism are significant influences in the manifestation of mental health symptoms (Lam, Yip, \& Gee, 2012). The African culture is defined as collectivist; self-concept is identified by attitudes toward family, material possessions, and an individual's social status (Berger, 2011; Carson, 2011). Initiation ceremonies and age sets are the organization and socialization structures used in African tribal communities; these stages in an individual's life determine their status in the community as well as how they are accepted by others (Berger, 2011).

On the other hand, North American culture is defined as individualist; this is where individuals focus more on their private self than their collective identity (Sue \& Sue, 2013). When the host culture is a huge departure from an immigrants known customs, the internal conflict is bound to cause some mental discord (Nwoye, 2009). Acculturative stress results from negative stereotypes and insolence held by the host culture about the immigrant population (Huang, Appel, \& Ai, 2011; Sirin, Patrice, \& Taveeshi, 2013). Scarcity of national resources can pressure social systems, compound job competition, and escalate social tensions in communities leading to immigrants being unserved or underserved as a result of the conflict (Ruiz et al., 2013). The evolving global crisis in migration is an overall phenomenon worldwide affecting most, if not all, Western countries; the emergence of 
immigrant communities or communities with immigrant background is a great challenge both for migrant and native European societies (Bándy, 2011). High unemployment among natives could increase the unwelcome temperament towards immigrants who are perceived as taking away job opportunities from the natives (Vidal, Martone, Muñoz, \& Grossman, 2011).

\section{Parenting and Socialization Challenges}

For immigrant and refugee families, parenting in a new culture can prove to be quite demanding (Bándy, 2011). The marginalization of immigrant parents renders them incapable of promoting their children's socialization and unable to help their children in learning the language of the host country (Bándy, 2011). The host nation's cultural environment, its morals and customs, are often inconsistent with the immigrant's parenting as the acculturation rate of parents and children differ, leading to difficulties and challenges especially in communication (Renzaho \& Vignjevic, 2011). Children tend to assimilate faster in a foreign culture due to the influence of daily schooling; they also lack the strong cultural connection their parents have to their country of origin (Renzaho \& Vignjevic, 2011). This often leads the immigrant youth to feel isolated from both the host country culture and their country of origin.

\section{Discrimination}

Those opposed to immigration have given a myriad of reasons to support their views. Some of the reasons given to oppose immigration are that migration is out of control, all immigrants and their children are newcomers who are unwilling to change over time, immigrants are segregated, poor, and a burden not needed (Malos, 2012; Nier, Gaertner, Nier, \& Dovidio, 2012; Tórrez, 2013). African Americans in the United States are reported as feeling more impacted by the arrival of immigrants than Whites, they fear they are likely to lose a job opportunity because an employer hired an immigrant worker (Tórrez, 2013).

When the arrival of the immigrants is treated with suspicion and mistrust, it makes for uncomfortable relationships between immigrants with their coworkers and neighbors (Díaz, 2011). Elevated risk for psychotic disorders was noted for different cultural groups, and was most serious for obvious minorities and other migrants who experienced greater cultural difficulties (Lanning, 2012; Melle et al., 2011).

\section{Immigration- and Age-Related Mental Health Issues}

The age at which one migrates has been found to be a significant factor in so far as mental health is concerned (Lam et al., 2012; Lau, Tsai, Liu, Hwang, \& Wei-Chin Takeuchi, 2013). Older immigrants were found to be more at risk for psychological health problems such as depressive symptoms and disorders, somatization, and culture specific localized patterns of psychological symptoms (TummalaNarra, Sathasivam-Rueckert, \& Sundaram, 2013). Older adult immigrants have been noted for underutilization of formal mental health services when compared with both the general immigrant population and nonimmigrant older adults (Tummala-Narra et al., 2013). Older immigrants who move to the United States later in life experience a number of stressors such as language barriers, difficulty navigating new cultural norms, dependence on adult children, changes in family structure and roles, and increased caregiving responsibilities for grandchildren (Tummala-Narra et al., 2013). Older immigrants are also likely to experience less financial independence and control, loss of authority, changes in family roles, intergenerational conflicts, limited ability to speak in English, and isolation (Tummala-Narra, et al., 2013). 


\section{Immigrant Youth}

Immigrant youth are more likely to experience academic struggle causing them to drop out without acquiring the necessary skills needed to compete in the knowledge intensive American society (Tórrez, 2013). Children whose parents are non-English speakers struggle in school and end up dropping out; in California, a quarter of the students have yet to master English (Tórrez, 2013). Learning a new language in school leaves little time to learn other academic subjects or socialize with English-speaking classmates, leading to inferior academic performance and estrangement from their peers (Tórrez, 2013). Juvenile delinquency, suicide, and drug use, leading up to adult criminality, are the likely results for the youth who drop out and have nowhere to turn for help (Koo, Peguero, \& Shekarkhar, 2012).

\section{Immigration and Mental Health Issues}

Migration trends are becoming progressively complicated in recent times; they not only involve refugees, but also many economic immigrants (United Nations High Commissioner for Refugees, 2014). There are approximately more than a million immigrants from Africa who currently reside in the United States; over half of them moved in the 10-year period from 1990 to 2000 (Venters \& Gany, 2011). Although the process of immigration results in opportunities for many families, there is significant stress involved in the journey (Suárez-Orozco \& Suárez-Orozco, 2001). Stressful life events can be extremely traumatic and can easily cause disturbing emotional fluctuations in a person's mental health and the entire quality of their life (Bjerre et al., 2013; Helms \& Guerda, 2012; Nwoye, 2009).

Anxiety and depression are two of the most common mental health conditions in the United States today (Masuda, Mandavia, \& Tully, 2014; Sánchez et al., 2014; Wright, Hallquist, Swartz, Frank, \& Cyranowski, 2014). This may be caused by any stressful factor in an individual's life, for example, the acculturation process of Brazilian and Latino immigrants in Massachusetts was found to play a role in the detriment of their mental health status (Sanchez et al., 2014). Acculturative stress, discrimination, language barriers, intergenerational family conflict, and socioeconomic barriers place immigrants at a higher risk of developing mental health problems (Idemudia, 2011; Park \& Kalibatseva, 2013; Sanchez et al., 2014).

\section{Theoretical Framework of Transition}

The literature reviewed revealed two main theories used in mental health and wellness: the transition theory and the social constructionism theory. Whereas change is often considered situational, transition is psychological (Bridges, 2004). An individual must go through internal modifications and self-resolve to integrate adjustments in life (Bridges, 2004). In his transitions theory, Bridges stated that an individual must let go of the old before beginning the new because that is the start of the transition. People utilize the style they have developed over the years for transitioning to endings (Bridges, 2004). Endings may make people fearful because disconnecting from the familiar can invoke old memories, hurt, and shame (Bridges, 2004). When people are in a fearful state, they are likely to abandon the three-phase process of ending, neutral zone, and beginning. Individuals may change the pattern, making transition unintelligible and frightening (Bridges, 2004). When individuals do not have access to assistance during this phase, psychological distress and physical ailments may occur.

The main goal of this qualitative study was to explore the impact of the immigration process on the mental health of Kenyan immigrants living in the Northeastern United States. Results of the study 
will facilitate the understanding of the lived experience of Kenyan immigrants who may be experiencing psychological distress issues as a result of the integration process. Although there are several research studies that focus on immigrants' mental health issues, most of the studies I found centered on the general population of Hispanics, Africans, or Eastern Europeans (Díaz, 2011; Koo et al., 2012; Makwarimba et al., 2013; Nwoye, 2009; Sirin et al., 2013; Tummala-Narra \& Claudius, 2013). There is a scarcity of information on the perspective of the Kenyan immigrant from the reviewed literature.

\section{Method}

\section{Participants}

Qualitative methods characteristically yield an abundance of detailed data about a much smaller number of people and cases (Patton, 2002). One general phenomenology research guideline is to collect extensive detail about each individual being studied (Creswell, 2009). The Northeastern United States was chosen in an effort to focus the research on one region of the United States. Phenomenology involves studying a small number of subjects to develop patterns and relationships of meaning (Creswell, 2009). I interviewed seven participants. Kenyan immigrants in this case were the empirical experts (Rudestam \& Newton, 2007). Purposeful sampling was used to identify individuals who can intentionally expose an appreciation of the research problem and the focal phenomenon in the study (Creswell, 2009).

The Walden University Review Board approved the procedure for this study including the consent forms for in-person and telephone interviews (Approval Number 10-01-15-0268043) before the data collection began. I then sent out flyers detailing the study's purpose and gave interested participants my contact information. The respondents were e-mailed the consent form. I contacted them to set up an interview time that was convenient for them after they consented to the study. The participants were Kenyan men and women who were over 18 years of age who immigrated permanently to the United States during the last 5 to 10 years. They also agreed to participate without compensation.

Descriptive or transcendental phenomenology was used to illuminate the feelings and attitudes of the participants' arising from their integration experiences. The focus of the study was on three areas: (a) the meaning Kenyan immigrants attach to their psychological distress, (b) what Kenyan immigrants believe may have caused any psychological distress they may have as a result of the integration process, and (c) the present feelings that Kenyan immigrants have toward the integration process.

\section{Research Questions}

The following were the research questions:

1. What is the lived experience of Kenyan immigrants' integration to the United States?

2. How does stress affect the mental functioning of Kenyan immigrants?

3. In what ways, if any, does the integration process impact the mental state of Kenyan immigrants? 


\section{Setting}

This phenomenological inquiry studied the impact of the immigration process on emerging psychosocial issues among Kenyan immigrants in the Northeastern United States. Therefore, the study was conducted among Kenyan immigrants who are currently residing in the United States. The use of telephone interviews allowed willing participants from any state in the Northeastern United States to take part. The study was open to Kenyan immigrants who may be residing in either rural or suburban areas as long as they had telephone access. Participants from diverse locations enriched the study by highlighting different integration experiences of the Kenyan immigrant.

\section{Data Collection}

Semistructured interviews using open-ended questions were the main source of data collection. To start the interview, participants were invited to discuss their background, age, sex, and other demographic information that was relevant to the study such as where they originally come from in Kenya and how they ended up in the United States. Six interview questions were spawned from the research questions and were used to guide the interview.

Based on the scope of the participants' responses, additional exploratory probes similar to "What was most supportive during your integration process?" and "Is there anything you wish you could change about your integration experience?" were asked. The interview was conducted by telephone. The recording was saved for transcribing before data analysis. The interview took between 30 and 45 min. English language was used to conduct the interviews. There were no data collected in Swahili, which is one of the official languages of Kenya, as all participants chose to communicate in English. Participants were given a list of mental health contacts in their area in case they experienced distress from answering the research questions.

\section{Data Analysis}

I began the data analysis by transcribing each interview and then performed a cross-case analysis to search for themes and patterns cutting across individual experiences (Cho \& Lee, 2014). This was achieved by providing a thorough account of each participant's narrative and the themes surrounding each case, followed by a thematic evaluation amongst the accounts of all participants (Creswell, 2009).

I used NVivo for data storage and management for quick and easy access to the information. This assisted by organizing the data to incite thoughts on the significance of each notion and sentence; the theory mapping attribute of this computer program assisted by categorizing determined codes first by ideas and then by topics (Creswell, 2007). Coding produced a knowledge source organized by groups, which was used to search for data repetitions and then incorporate established patterns into an organized theoretical description (Gläser \& Laudel, 2013). Validity was ascertained by e-mailing each participant a summary of their interview to determine that their views had been interpreted correctly. Where necessary, I made modifications based on the feedback I got from the participants. I used pseudonyms when referring to each participant. 


\section{Results}

\section{Research Question 1}

The first research question was "What is the lived experience of Kenyan immigrants' integration into the United States?" The first three interview questions were designed to answer this question. These were some of the responses from the participants: “...being illegal (immigrants) and during that time we had gone for our interview and we didn't know where we were standing as yet we were kicked out of our home..."; "The greatest challenge is my accent, the fact is when I try to speak like an American, am not..."; "It was difficult getting a fair job, I mean I was a lecturer (college professor) back home but when I came, I had to work as a security guard..."

From the responses to these three interview questions, several themes emerged from the participants' integration experiences: discrimination, exploitation, social support, exclusion, culture shock, shame, disenchantment, and overcompensation. One participant had regrets due to the "mental damage" caused by the integration process, she expressed that if she knew what she did now and stayed in Kenya, she would be further along and happier in life. To her, the "problems and hatred encountered as a new immigrant" did not make the experience worthwhile. Despite most participants feeling challenged during their transition process, six of the seven participants were still glad they made the move to America and felt that everything eventually worked out.

\section{Research Question 2}

The second research question was "How does stress affect the mental functioning of Kenyan immigrants?" The interview question proposed to answer this question was "How would you describe your mental state during the most challenging times of your integration?" The participants had varied answers in response to this question: "You feel like you want to quit"; "My mental state was quite unstable... as a result I started getting frustrated, depressed, and so forth..."; "It was stressful, very stressful especially when you really need something like you need a job, you can't get a job..." One participant understood mental state to also mean her spiritual wellbeing, and so for her, she left everything to God during those trying times. All the other participants used terms like stressful, depressing, difficult, sad, unstable, angry, and homesick to describe their mental state during their most trying transition period. Imani is a 42 -year-old woman who identified as a Kenyan immigrant. She is divorced and moved to the United States more than 10 years ago. As an immigrant, she stated that she

encountered a lot of hatred, we have to persist and work extra hard than a normal person because first you have your accent, then you have your color and everything that I own I had to really fight for it.

\section{Research Question 3}

The third research question was "In what ways, if any, does the integration process impact the mental state of Kenyan immigrants?" The interview question "What impact has the integration process had on your mental functioning?" was asked. One participant responded that her faith and belief in God gave her a calm mental state, while another participant stated that it had gotten easier over the years and her mental health had gotten better after learning to cope and live in the United States for a longer period. Anxiety, pressure, confusion, stressful, and depression were terms used by four participants when talking about the effect of the integration process on their mental state. One participant who had lived in the United States for long still felt unwelcome, she reported, 
...but people they have a way of making you know you are different and that is where it was so hard because back home you don't have to be reminded you are different, nobody cares but then you come here and you are constantly reminded that by the people around you, by the community that you are different, "you have an accent" "where are you from" so there's always something to remind you that you are not home.

As an immigrant, she reports that "people don't expect you to be very aware of what's going on around you, people don't expect you to really know your rights."

Despite the psychosocial issues faced during their integration process, the participants did not mention seeking any type of mental health services. Two of the participants came in to the United States as students and expressed facing financial difficulties while paying their way through school, seeking medical services was viewed as a luxury they could not afford. Figure 1 summarizes the impact of the integration process on the participant's psychosocial health.

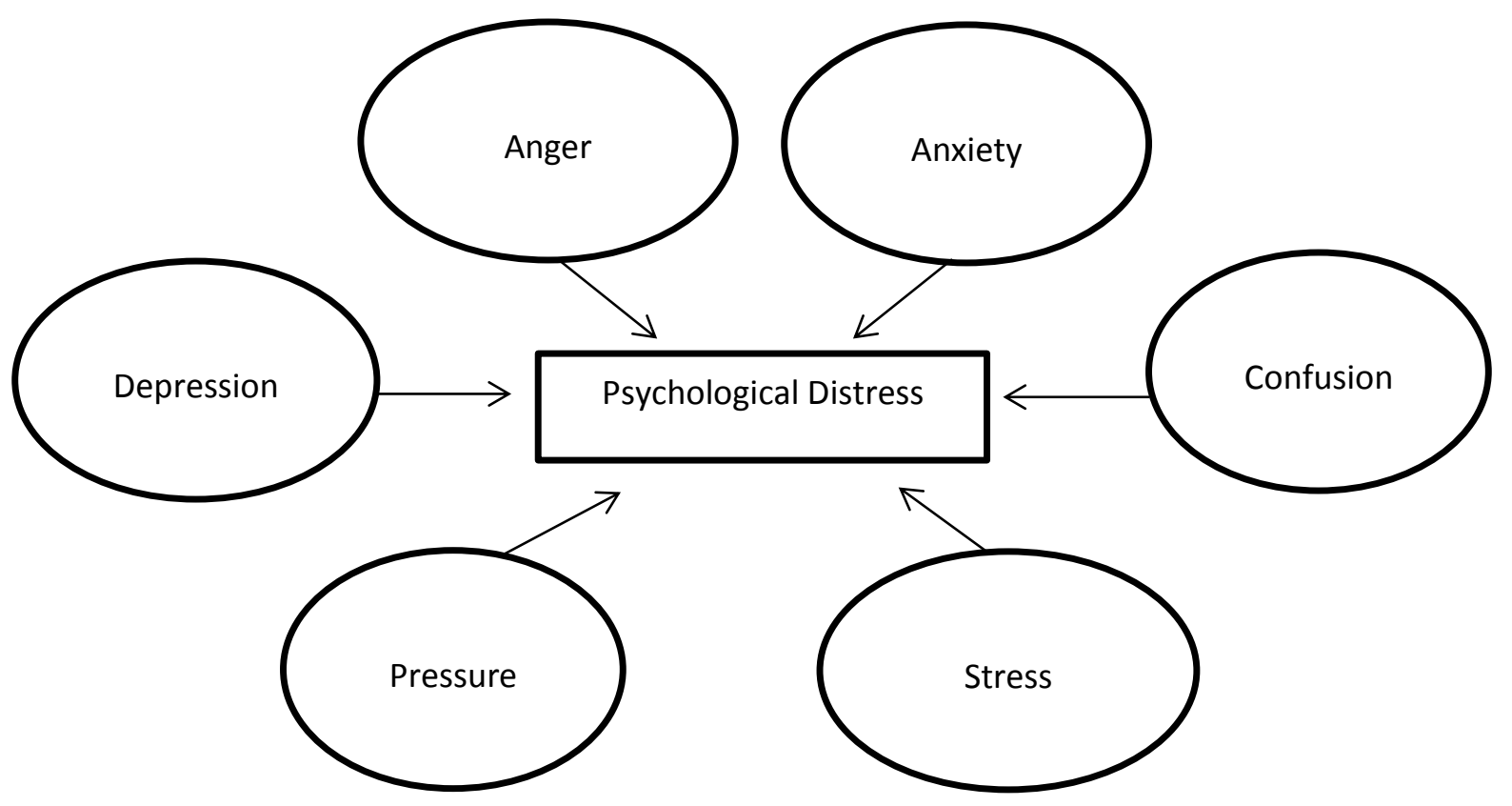

Figure 1. Impact of Integration Process on Participant's Mental State

\section{Themes}

The purpose of the study was to investigate the perspectives and lived experience of seven Kenyan immigrants and how stress from the integration process could lead to psychological distress. I performed verbatim scrutiny of the interviews by categorizing significant words and phrases in search of patterns, relationships, and themes both between and within stories of the immigrants (Leech \& Onwuegbuzie, 2011). I identified eight major themes: culture shock, discrimination, exploitation, shame, disenchantment, overcompensation, economic pressure, and social support. The themes were noted during the most trying times of the transition process. 


\section{Discussion}

While answering the interview questions, most of the participant's narratives had a theme of disenchantment or disillusion. Disillusion or disenchantment are the feelings experienced by immigrants when they realize that ideas and thoughts they had before migrating are often idealistic and unrealistic (Atsushi, 2014). Nwoye (2009) found that there is often a great mismatch between the reality on the ground and the ideas the immigrants had before making the move. The participants in this study cited images from television programs, movies, and stories they heard as giving them hope that their migration experience will be easy and lead to a prosperous life. The reality is that the participants faced estrangement from the mainstream culture, and some middleclass migrants had to take nonprofessional jobs, thus experiencing downward mobility (Atsushi, 2014). Prior to immigrating, the ideal life in the West is described using words such as stylish, lively, and exciting, while affirmative pictures of the West additionally breed glowing ideas of settlement (Atsushi, 2014).

Discrimination is another theme that emerged from the participants' experiences of integration. Perceived discrimination may be regarded as the individual discernment of an unfavorable and prejudiced treatment which impacts ethnic groups, based on ethnic-racial injustices, and national or ethnic origins leading to a harmful effect on members of the subordinate group (Mendes \& Candeias, 2013). One participant stated that the jobs and kind of housing they had to take during their transition period were not what everyone else in the community had. Another participant reported that she was denied a promotion after working for the same company for 11 years because she was an immigrant. This is similar to what was found in earlier studies. Minority groups experience discrimination based on their minority status (Otiniano, Gee, Ford, \& Iguchi, 2014). Zeiders, Doane, and Roosa, (2012) found that experiences of discrimination are associated with perceived stress. Moreover, discrimination is associated with numerous stress-related consequences, ranging from psychological distress to cardiovascular disorders (Otiniano et al., 2014).

Culture shock can be defined as the cultural awkwardness that occurs when people are relocated from their habitual traditional setting to a different culture where they may not understand evident indications and signs of social communication, interactive procedures, and laws (Winbush \& Selby, 2015). This shock pervades all areas of an immigrant's life. The participants in the study experienced this in varied ways. Some expressed shock at the mode of dressing, others were concerned that their children would grow up to adapt the "foreign" culture and forget their Kenyan identity. Even though Kenya is an English-speaking country, and all the participants could communicate in English prior to their arrival in the country, they were still shocked by the attitude of the natives toward their accents when they spoke. For one participant, this was of major concern to her and it took her over 5 years to feel comfortable communicating in English.

The loss and grief experience, stress from the changing environment, and the demands of integrating into a new culture, like work, schooling, and socializing all result in a high level of anxiety in both children and adults (Winbush \& Selby, 2015). Culture shock can cause behavioral uncertainty and confounded cognitive functioning (Winbush \& Selby, 2015). Immigrants are forced to adjust from identity security to identity insecurity and unacquaintedness (Sawicky, 2011). A steady identity conversion takes place which leaves the immigrant with a higher degree of identity susceptibility; this vulnerability could lead to anxiety and depression when coping becomes difficult (Winbush \& Selby, 2015).

Some participants expressed that they were taken advantage of because they were new to the country and did not know all the laws that could help protect them. Most experienced this at their 
initial places of employment by reporting that they felt taken advantage of. This was also the case for participants who came to the United States as students and did not have work permits.

Exploitation of immigrants has gone on for a long period of time. Refugees and immigrants represent a resource that is quite susceptible to exploitation, subsequently refugees and other immigrants take the jobs that most Americans will disregard usually involving physical labor at low pay, and many times work in notably subpar conditions, such as in plants and other corporate facilities (Vachon, 2013). Exploitation of immigrants occurs when they are offered low salaries because they have little recourse for legal action since they lack legal status (Manik, 2014). From the narratives of the participants in the story, some stated they were exploited even though they had legal documents to work in the country.

Kenyans are considered a collectivist culture. Most people from collectivist cultures will not seek help and generally will avoid self-disclosure about experiencing distress because of the shame associated with mental illness and the importance of the family name (Han \& Oliffe, 2015). It is interesting to note that this theme of shame came from the only two male participants in the study. Even though they experienced difficult times and considered going back to Kenya, the thought of going back with nothing to show was worse than the problems they faced during their transition process. It is important to recognize these cultural norms while considering other sociocultural contexts, as well as the importance of family cohesion stemming from collectivist and interdependent cultural orientations when developing intervention programs for Kenyan immigrants who may face mental health crisis arising from the shame of not being perceived a success (Sue \& Sue, 2013).

Most immigrants experience the devaluation of their foreign education and work experience and consequently face difficulties while obtaining occupational licenses, these impedes their labor market integration while complicating their pursuit of educational upgrading courses (Tungohan et al., 2015). While the immigrant is trying to get meaningful work, they are still the only income earners for their families in the United States, and often times also for the extended family back home. Two participants in this study reported that they had to work extra hard to prove that they were deserving of the jobs they had. In some cases, one's gender had an effect on the psychological distress; women who lacked extended family support were found to be at a higher risk for psychological distress, while men experienced more distress when they had conflict with family culture and lower community social position (Hong, Walton, Tamaki, \& Sabin, 2014). One participant found her integration experience more difficult for being a single parent, while another stated that being a single lady makes her a target for exploitation. There is an increased rate of divorce, aggressiveness, suicide attempts, personal relations problems, anxiety, and a resolve to return to their home country among different groups of immigrants (Jafari, Baharlou, \& Mathias, 2010). The participants in the study expressed facing anxiety and depression at some point during their integration process. Bridges, Arellano, Rheingold, Danielson, and Silcott (2010) suggested that immigrants could be at a greater chance for suppressing ailments, such as depression and anxiety but decreased chance for externalizing disorders, such as drug and alcohol use. They also found that immigrants with a great need for mental health services access medical and psychiatric services considerably less often as a result of fear of being deported, mistrust of service providers, and the dread of law enforcement officials (Bridges et al., 2010). Additionally, immigrants are normally unemployed or underemployed compared to other minority groups in the United States, and so may not have sufficient health coverage.

The extent to which immigrants are able to integrate into any host society depends on the nature of spatial and societal integration available, visible minorities experience discrimination and exclusion, making integration into the host community difficult (Zaami, 2015). One participant described her alienation experience as not being totally accepted by either white or black communities in the 
Unites States leaving her in a cultural limbo. Agrawal (2010) found that some dominant groups avoid contact with minority members to defend and preserve their cultural distinctiveness.

The habitual censure, shame, and intricately cultivated laws of deportable foreigners also supply the justification for dispensing juridical inequalities of citizenship and alienage as resounding differences that may be racialized (De Genova, 2013). Immigrants develop a fluid sense of belonging when the host country does not offer them a viable place to belong, this often results in individuals' alternative formulations of belonging to cope with exclusion and discrimination by reframing and compartmentalizing a more inclusive and emotional dimension of fitting in (Kılıç \& Menjívar, 2013).

Social support is a theme that recurred in most participants' narratives. Having social support or not having any social support made a difference in the integration experience of the participants. The participants who had social support either through relatives or other Kenyans immigrants reported that the support made their integration experience easier while those without reported feeling isolated and alone in their experience. This is not unlike what is in the literature, Ayón and Naddy (2013) found that social support can have positive outcomes such as feeling cared about and the ability to talk to someone when stressors increase, as well as negative outcomes such as feeling tense, being criticized, and being let down.

Both the positive and negative aspects of social relationships with family and friends can impact individuals' ability to cope with minority stress (Ayón \& Naddy, 2013). Furthermore, the strength of such relationships may be more important as protective factors against psychological distress for individuals belonging to minority groups (Lee \& Woo, 2013).

Thus, immigrants may turn to their social network members for support in a time of need, but members may already be highly taxed or experiencing similar problems (Ayón \& Naddy, 2013). This was the case for one of the participants in the study, who reported she overstayed her welcome with a relative which led to a fall out in their relationship which she still has not been able to reconcile. However, in most cases social support network is associated with enhanced improvement in health, better employment opportunities and positive parenting practices, which promote family welfare (Ayón \& Naddy, 2013; Hurtado-de-Mendoza, Gonzales, Serrano, \& Kaltman, 2013; Viruell-Fuentes, Morenoff, Williams, \& House, 2013).

The transitions theory by Bridges (2004) formed the theoretical framework for this study. According to Bridges, it is the internal modifications and self-resolve that an individual must go through to integrate any of those adjustments in life. The transition theory has three stages: the ending, neutral zone, and new beginnings (Bridges, 2004). From the participant's stories, the ending appears to be the stage at which immigrants may experience the most distress. This is because endings typically make people apprehensive because they are severed from what they have become very familiar with sometimes awakening old memories of hurt and shame (Bridges, 2004). This would explain the culture shock experience which all the participants alluded to in their accounts of their integration experience.

The participants all migrated in their adult years and so they had grown up accustomed to doing everything in a particular way, but with the migration they are forced to adapt to a new culture and way of being to survive. In fear, individual's may abandon the three-phase process of ending, neutral zone, and beginning, or even twist the pattern around making transition unintelligible and frightening (Bridges, 2004). The confusion could explain the themes of exclusion, overcompensation, and disenchantment that the participants faced during the difficult times of their integration experience. This is also the point at which mental health and sometimes physical illnesses are likely to set in if an individual is not able to cope or seek help. 
From the participants account, most found a way to cope through social support and religion. Majority of the participants expressed that with time things got easier because none expressed the idea of going back to Kenya as an option even though some mentioned knowing Kenyans who had moved back to Kenya when situations were not manageable. The most trying times of the integration process could also be likened to Draper's (2003) liminality phase during transition; this is when feelings of marginality and vulnerability abound due to decrease in social emotional support while trying to establish oneself in a new social hierarchy and the distress caused while renegotiating relationships (Shell, Gazelle \& Faldowski, 2014).

The thesis of social constructivism is that individual thoughts seldom reflect reality, but rather the mind envisions and recreates experiences (Schneider, 2004). The mind organizes and order experiences to form knowledge which may be contrary to an individual's outward experiences (Schneider, 2004). Mental models are shared and culturally biased in the way we perceive and organize experience; the mental patterns individuals engage in are socially learned and influenced by socialization, religion, educational achievement, and other life experiences (Werhane et al., 2011). This model can also apply to the participants' experiences because their view of the integration experience was culturally biased but with time they adjusted their mental styles and patterns of recognition to better cope with their new reality. This could also explain the variations in experiences as perceived by the immigrants, each immigrant viewed their new environment through culturally biased mental models.

The findings of the study are based on a small sample $(n=7)$ of Kenyan men and women. The participants are considered subject matter experts even though the sample was small. All the participants live in the Northeastern region of the United States, future studies on Kenyan immigrants may be conducted in the Western, Southern, Northwest, and Midwestern regions of the United States to get the lived experience of immigrants in those regions. The study had participants ranging in age from 39 to 51 years; younger immigrants were not included. Future studies on the same issue could consider younger Kenyan immigrants. The study only had two male participants; future studies may consider focusing on male immigrants to find out more on how they perceive their integration experience.

The interviews were conducted via telephone due to the different locations where each participant lives; nonverbal reactions and in-person observations were not perceived even though sighs, long pauses, and laughter were noted. Most of the participants had already lived in the country between 5 and 10 years; future studies may consider case studies of Kenyan immigrants who have just arrived in the country to study their lived experience during the first year, which was cited as being the most challenging by the participants. Immigrants deal with stressors such as the loss of cultural identity, acculturation, cultural displacement, and loss of role and status in the family, which negatively impact them by undermining their sense of self and psychological health (Mui \& Lee, 2014). 


\section{References}

Agrawal, S. K. (2010). Neighbourhood patterns and housing choices of immigrants. Brampton, Ontario, Canada: Region of Peel Human Services. Retrieved from https://www.peelregion.ca/social-services/pdfs/discussion-paper-4.pdf

Amuedo-Dorantes, C., Puttitanun, T., \& Martinez-Donate, A. (2013). How do tougher immigration measures affect unauthorized immigrants? Analyses of Social Issues \& Public Policy, 50, 1067-1091. doi:10.1111/j.1530-2415.2011.01271.x

Atsushi, T. (2014). Japanese marriage migrants in "imagined" multicultural Australia Facing gaps between expectation and reality. Crossings: Journal of Migration \& Culture, 5, 257-272. doi:10.1386/cjmc.5.2-3.257_1

Ayón, C., \& Naddy, M. (2013). Latino immigrant families' social support networks: Strengths and limitations during a time of stringent immigration legislation and economic insecurity. Journal of Community Psychology, 41, 359-377. doi:10.1002/jcop.21542.

Bándy, K. (2011). The challenges of the European Union's migration and integration policy: The road to a common immigration policy. Sociology Study, 1, 415-429.

Berger, K. S. (2011). Immigration, psychosocial development: Implications for Africa and the U.S. İrinkèrindò: A Journal of African Migration, 4, 1-30.

Bjerre, S. S., Dauvrin, N. V., Dias, M., Gaddini, S., Greacen, A., Ioannidis, T., ... Stefan, M. P. (2013). Experiences with treating immigrants: A qualitative study in mental health services across 16 European countries. Social Psychiatry and Psychiatric Epidemiology, 48, 105-116.

Bridges, A. J., Arellano, M. A., Rheingold, A. A., Danielson, C. K., \& Silcott, L. (2010). Trauma exposure, mental health, and service utilization rates among immigrant and United Statesborn Hispanic youth: Results from the Hispanic family study. Psychological Trauma: Theory, Research, Practice, and Policy, 2, 40-48.

Bridges, W. (2004). Managing transitions: Making the most of change (2nd ed.). New York, NY: Da Capo.

Carson, J. C. (2011). "Africa” in Minnesota: New models of translocal culture. İrìnkèrindò: A Journal of African Migration, 4, 1-11.

Cho, J. Y., \& Lee, E. (2014). Reducing confusion about grounded theory and qualitative content analysis: Similarities and differences. Qualitative Report, 19, 1-20.

Creswell, J. W. (2007). Qualitative inquiry research design: Choosing among five approaches (2nd ed.). Thousand Oaks, CA: Sage.

Creswell, J. W. (2009). Research design: Qualitative, quantitative, and mixed methods approaches (3rd ed.). Thousand Oaks, CA: Sage.

David, E. J., Nadal, R., \& Kevin, L. (2013). Cultural diversity and ethnic minority psychology. New Developments in Research on Immigration, 19, 298-309.

De Genova, N. (2013). Spectacles of migrant "illegality": The scene of exclusion, the obscene of inclusion. Ethnic \& Racial Studies, 36, 1180-1198. doi:10.1080/01419870.2013.783710

Díaz, J. (2011). Immigration policy, criminalization and the growth of the immigration industrial complex: Restriction, expulsion, and eradication of the undocumented in the U.S. Western Criminology Review, 12, 35-54. doi:10.1177/1534765610396728 
Draper, J. (2003). Men's passage to fatherhood: An analysis of the contemporary relevance of transition theory. Nursing Inquiry, 10, 66-78. doi: 10.1046/j.1440-1800.2003.00157.x

Gläser, J., \& Laudel, G. (2013). Life with and without coding: Two methods for early-stage data analysis in qualitative research aiming at causal explanations. Qualitative Social Research, $14,1-37$.

Goff, L., Zarin, H., \& Goodman, S. (2012). Climate-induced migration from Northern Africa to Europe: Security challenges and opportunities. Brown Journal of World Affairs, 18, 195-213.

Gringeri, C., Barusch, A., \& Cambron, C. (2013). Examining foundations of qualitative research: A review of social work dissertations, 2008-2010. Journal of Social Work Education, 49, 760773. doi:10.1080/10437797.2013.812910

Han, C. S., \& Oliffe, J. L. (2015). Korean-Canadian Immigrants' help-seeking and self-management of suicidal behaviors. Canadian Journal of Community Mental Health, 34, 17-30. doi:10.7870/cjcmh-2014-036

Hazzan, O., \& Nutov, L. (2014). Teaching and learning qualitative research, conducting qualitative research. Qualitative Report, 19, 29.

Helms, J. E. N., \& Guerda, G. C. E. (2012). Racism and ethno violence as trauma: Enhancing professional and research training. Traumatology, 18, 65-74.

Hong, S., Walton, E., Tamaki, E., \& Sabin, J. A. (2014). Lifetime prevalence of mental disorders among Asian Americans: Nativity, gender, and socio demographic correlates. Asian American Journal of Psychology, 5, 353-363.

Huang, B., Appel, H., \& Ai, A. (2011). The effects of discrimination and acculturation to service seeking satisfaction for Latina and Asian American women: Implications for mental health professions. Social Work in Public Health, 26, 46-59.

Hurtado-de-Mendoza, A., Gonzales, F., Serrano, A., \& Kaltman, S. (2013). Social isolation and perceived barriers to establishing social networks among Latina immigrants. American Journal of Community Psychology, 53, 73-82. doi:10.1007/s10464-013-9619-x.

Idemudia, E. S., Williams, J. K., \& Wyatt, G. E. (2013). Migration challenges among Zimbabwean refugees before, during and post arrival in South Africa. Journal of Injury \& Violence Research, 5, 17-27. doi:10.5249/ jivr.v5i1.185

Idemudia, E. S. (2011). Value orientations, acculturative stress and mental health among African German immigrants. Journal of Psychology in Africa, 21, 441-445.

Jafari, S., Baharlou, S., \& Mathias, R. (2010). Knowledge of determinants of mental health among Iranian immigrants of BC, Canada: A qualitative study. Journal of Immigrant and Minority Health, 12, 100-106.

Karanja, A. (2014). 250,000 Kenyans entered U.S. in last twenty years: Report. Daily Nation. Retrieved from http://www.nation.co.ke/news/diaspora/kenyans-US-visas-embassyimmigration-green-card/-/2107720/2193676/-/jxkn3g/-/index.html

Katsiaficas, D., Suárez-Orozco, C., Sirin, S., \& Gupta, T. (2013). Mediators of the relationship between acculturative stress and internalization symptoms for immigrant origin youth. Cultural Diversity \& Ethnic Minority Psychology, 19, 27-37. doi:10.1037/a0031094

Kılıç, Z., \& Menjívar, C. (2013). Fluid adaptation of contested citizenship: Second-generation migrant Turks in Germany and the United States. Social Identities, 19, 204-220. doi:10.1080/13504630.2013.789217. 
Konadu-Agyemang, K., Takyi, B. K., \& Arthur, J. A. (2006). The new African diaspora in North America: Trends, community building and adaptation. Lanham, MD: Lexington Books.

Koning, E. A. (2011). Ethnic and civic dealings with newcomers: Naturalization policies and practices in twenty-six immigration countries. Ethnic \& Racial Studies, 34, 1974-1994. doi:10.1080/01419870.2011.556747

Koo, D. J., Peguero, A. A., \& Shekarkhar, Z. (2012). Gender, immigration, and school victimization. Victims \& Offenders, 7, 77-96, doi:10.1080/15564886.2011.629773

Lam, J., Yip, T., \& Gee, G. (2012). The physical and mental health effects of age of immigration, age, and perceived difference in social status among first generation Asian Americans. Asian American Journal of Psychology, 3, 29-43.

Lanning, K. (2012). Social psychology and contemporary immigration policy: An introduction. Analyses of Social Issues \& Public Policy, 12, 1-4. doi:10.1111/j.1530-2415.2011. 01271.x

Lau, A. S., Tsai, W. S., Liu, J., Hwang, L. L., \& Wei-Chin Takeuchi, D. T. (2013). The immigrant paradox among Asian American women: Are disparities in the burden of depression and anxiety paradoxical or explicable? Journal of Consulting and Clinical Psychology, 81, 901911.

Leech, N. L., \& Onwuegbuzie, A. J. (2011). Beyond constant comparison qualitative data analysis: Using Nvivo. School Psychology Quarterly, 26, 70-84. doi:10.1037/a0022711

Lister, M. (2010). Immigration, association, and the family. Law \& Philosophy, 29, 717-745. doi:10.1007/s10982-010-9083-9

Malos, S. (2012). Employment discrimination based on immigration status: Recent cases involving H-1B visas. Employee Responsibilities \& Rights Journal, 24, 23-36. doi:10.1007/s10672-0119175-1

Makwarimba, E., Stewart, M., Simich, L., Makumbe, K., Shizha, E., \& Anderson, S. (2013). Sudanese and Somali refugees in Canada: Social support needs and preferences. International Migration, 51, 106-119. doi:10.1111/imig.12116.

Manik, S. (2014). Teško preživljavamo od svoga rada«: iskustva zimbabveanskih učitelja kao ranjive skupine u Južnoafričkoj Republici ["We are working hand to mouth": Zimbabwean teachers' experiences of vulnerability in South Africa]. Migracijske i etnicke teme [Migration and Ethnic Themes], 30, 171-191. doi:10.11567/met.30.2.3

Masuda, A., Mandavia, A., \& Tully, E. C. (2014). The role of psychological inflexibility and mindfulness in somatization, depression, and anxiety among Asian Americans in the United States. Asian American Journal of Psychology, 5, 230-236. doi:10.1037/a0034437

McCabe, K. (2011). African immigrants in the Unites States. Retrieved from http://www.migrationpolicy.org/article/african-immigrants-united-states

Melle, B. A. O., Rossberg, I., Romm, J. R., Larsson, K. L., Lagerberg, S., Andreassen, T. V., \& Edvard, O. A. H. (2011). Perceived discrimination is associated with severity of positive and depression/anxiety symptoms in immigrants with psychosis: A cross-sectional study. BMC Psychiatry, 11, 1-9.doi:10.1186/1471-244X-11-77

Mendes, M. M., \& Candeias, P. (2013). Immigrant perceptions of ethnic and racial discrimination: patterns and singularities in a municipality in the Lisbon Metropolitan Area. International Review of Sociology, 23, 401-420. doi:10.1080/03906701.2013.804299 
Mui, A., \& Lee, E. (2014). Correlates of depression among Chinese and Korean immigrant elders in the United States. Ageing International, 39, 274-288. doi:10.1007/s12126-013-9183-6

Nier, J. A., Gaertner, S. L., Nier, C. L., \& Dovidio, J. F. (2012). Can racial profiling be avoided under Arizona immigration law? Lessons learned from subtle bias research and anti-discrimination Law. Analyses of Social Issues \& Public Policy, 12, 5-20.

Nwoye, A. (2009). Understanding and treating African immigrant families: New questions and strategies. Psychotherapy \& Politics International, 7, 95-107. doi:10.1002/ppi.188

Otiniano V. A. D., Gee, G. C., Ford, C. L., \& Iguchi, M. Y. (2014). Racial discrimination, gender discrimination, and substance abuse among Latina/os nationwide. Cultural Diversity \& Ethnic Minority Psychology, 20, 43-51. doi:10.1037/a0034674

Park, L. F., \& Kalibatseva, Y. S. (2013). Disentangling immigrant status in mental health: Psychological protective and risk factors among Latino and Asian American immigrants. American Journal of Orthopsychiatry, 83, 361-371.

Passel, J. S., \& Cohn, D. (2012). U.S. foreign-born population: How much change from 2009 to 2010 ? Washington, DC: Pew Hispanic Center. Retrieved from http://www.pewhispanic.org/files/2012/01/Foreign-Born-Population.pdf

Patton, M. Q. (2002). Qualitative research and evaluation methods (3rd ed.). Thousand Oaks, CA: Sage Publications, Inc.

Poortman, C., \& Schildkamp, K. (2012). Alternative quality standards in qualitative research? Quality \& Quantity, 46, 1727-1751. doi:10.1007/s11135-011-9555-5

Renzaho, A. M. N., \& Vignjevic, S. (2011). The impact of a parenting intervention in Australia among migrants and refugees from Liberia, Sierra Leone, Congo, and Burundi: Results from the African Migrant Parenting Program. Journal of Family Studies, 17, 71-79. doi:10.5172/jfs.2011.17.1.71

Rudestam, K. E., \& Newton, R. R. (2007). Surviving your dissertation: A comprehensive guide to content and process (3rd ed.). Thousand Oaks, CA: Sage.

Ruiz, J. M., Gallardo, M. E., \& Delgado-Romero, E. A. (2013). Latinas/os and immigration reform: A commentary to "Crossroads: The psychology of immigration in the new century"-The report of the APA Presidential Task Force on Immigration. Journal of Latina/o Psychology, 1, 149154. doi:10.1037/lat0000002

Sánchez, M. C., Esteban, A., Calista, S. T., Connell, J. L., DePalo, J., Ferreira, A., ... Rivera, E. I. (2014). Brave new world: Mental health experiences of Puerto Ricans, immigrant Latinos, and Brazilians in Massachusetts. Cultural Diversity and Ethnic Minority Psychology, 20, 1626. doi:10.1037/a0034093

Schneider, J. W. (2004). Social constructionism. Encyclopedia of Social Theory. Retrieved from www.encyclopedia.com/topic/Social_constructionism.aspx

Shell, M. D., Gazelle, H., \& Faldowski, R. (2014). Anxious solitude and the middle school transition: A diathesis $\times$ stress model of peer exclusion and victimization trajectories. Developmental Psychology, 50, 1569-1583. doi:10.1037/a0035528.

Sawicky, W. (2011). We are not like other people: Identity loss and reconstruction following migration. In D. L. Harris (Ed.), Counting our losses: Reflecting on change, loss and transition in everyday life (pp. 151-161). New York, NY: Routledge. 
Sirin, S. R. R., Patrice, G., \& Taveeshi, R. L. (2013). The role of acculturative stress on mental health symptoms for immigrant adolescents: A longitudinal investigation. Developmental Psychology, 49, 736-748.

Suárez-Orozco, C., \& Suárez-Orozco, M. (2001). Children of immigration. Cambridge, MA: Harvard University Press.

Sue, D. W., \& Sue, D. (2013). Counseling the culturally diverse: Theory and practice (6th ed.) New York, NY: John Wiley \& Sons.

Thomas, K. J. (2011). What explains the increasing trend in African emigration to the U.S.? International Migration Review, 45, 3-28. doi:10.1111/j.1747-7379.2010. 00837.x

Tórrez, N. (2013). Education and immigration in California: Key trends. National Social Science Journal, 40, 107-113.

Tuckman, B. W. (1999). Constructing research designs. Conducting Educational Research, 5, 159196.

Tummala-Narra, P., Sathasivam-Rueckert, N., \& Sundaram, S. (2013). Voices of older Asian Indian immigrants: Mental health implications. Professional Psychology: Research and Practice, 44, $1-10$

Tungohan, E., Banerjee, R., Wayne C., Cleto, P., De Leon, C., Garcia, M., ... Sorio, C. (2015). After the live-in caregiver program: Filipina caregivers' experiences of graduated and uneven citizenship. Canadian Ethnic Studies, 47, 87-105.

United Nations High Commissioner for Refugees. (2014). Flowing across borders. Retrieved from http://www.unhcr.org/pages/49c3646c125.html

Vachon, C. (2013). Burma just around the corner: When U.S. corporations employ refugees. Wisconsin Journal of Law, Gender \& Society, 28, 159-180.

Venters, H., \& Gany, F. (2011). African immigrant health. Journal of Immigrant \& Minority Health, 13, 333-344. doi:10.1007/s10903-009-9243-x

Vidal, H. M., Martone, J., Muñoz, L., \& Grossman, S. (2011). Family cohesion and social support: Protective factors for acculturation stress among low-acculturated Mexican migrants. Journal of Poverty, 15, 403-426. doi:10.1080/10875549.2011.615608

Viruell-Fuentes, E. A., Morenoff, J. D., Williams, D. R., \& House, J. S. (2013). Contextualizing nativity status, Latino social ties, and ethnic enclaves: An examination of the "immigrant social ties hypothesis.” Ethnicity \& Health, 18, 586-609. doi:10.1080/13557858.2013.814763

Wang, T., \& Lien, Y. (2013). Erratum to: The power of using video data. Quality \& Quantity, 47, 2943. doi:10.1007/s11135-012-9776-2

Werhane, P.H., Hartman, L. P., Moberg, D., Englehardt, E., Pritchard, M., \& Parmar, B. (2011). Social constructivism, mental models, and problems of obedience: Pathos for ethics, business excellence, leadership and quest for sustainability. Journal of Business Ethics, 100, 103-118. doi:10.1007/s10551-011-0767-3

Winbush, C., \& Selby, R. (2015). Finding home: South African migration to New Zealand. Aotearoa New Zealand Social Work Review, 27, 46-58.

Wright, A. G. C., Hallquist, M. N., Swartz, H. A., Frank, E., \& Cyranowski, J. M. (2014). Treating cooccurring depression and anxiety: Modeling the dynamics of psychopathology and psychotherapy using the time-varying effect model. Journal of Consulting and Clinical Psychology, 82, 839-853. doi:10.1037/a0034430 
Zaami, M. (2015). "Fit the description": Experiences of social and spatial exclusion among Ghanaian immigrant youth in the Jane and Finch neighborhood of Toronto. Canadian Ethnic Studies, 47, 69-89.

Zeiders, K. H., Doane, L. D., \& Roosa, M. W. (2012). Perceived discrimination and diurnal cortisol: Examining relations among Mexican American adolescents. Hormones and Behavior, 61, 541-548. doi: 10.1016/j.yhbeh.2012.01.018

The Journal of Social, Behavioral, and Health Sciences is an open-access, peer-reviewed, online interdisciplinary journal focusing on research findings that address contemporary national and international issues. Its objectives are to (a) encourage dialogue between scholars and practitioners in the social, behavioral, and health sciences that fosters the integration of research with practice; (b) promote innovative models of interdisciplinary collaboration among the social, behavioral, and health sciences that address complex social problems; and (c) inform the relationship between practice and research in the social, behavioral, and health sciences.

Walden University Publishing: http://www.publishing.waldenu.edu 